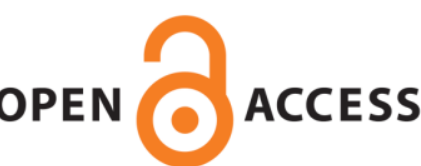

UWS Academic Portal

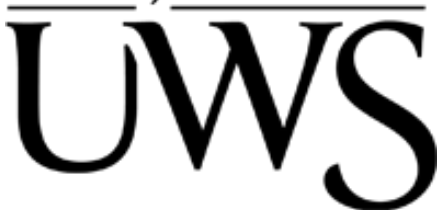

\title{
Modelling and optimization of wet microalgae Scenedesmus quadricauda lipid extraction using microwave pre-treatment method and response surface methodology Onumaegbu, C.; Alaswad, A.; Rodriguez, C.; Olabi, A.
}

Published in:

Renewable Energy

DOI:

10.1016/j.renene.2018.09.008

Published: 31/03/2019

Document Version

Peer reviewed version

Link to publication on the UWS Academic Portal

Citation for published version (APA):

Onumaegbu, C., Alaswad, A., Rodriguez, C., \& Olabi, A. (2019). Modelling and optimization of wet microalgae Scenedesmus quadricauda lipid extraction using microwave pre-treatment method and response surface methodology. Renewable Energy, 132, 1323-1331. https://doi.org/10.1016/j.renene.2018.09.008

\section{General rights}

Copyright and moral rights for the publications made accessible in the UWS Academic Portal are retained by the authors and/or other copyright owners and it is a condition of accessing publications that users recognise and abide by the legal requirements associated with these rights. 
Modelling and optimization of wet microalgae Scenedesmus quadricauda lipid extraction using microwave pre-treatment method and response surface methodology

\section{Onumaegbu ${ }^{1}$, A. Alaswad ${ }^{2}$, C. Rodriguez ${ }^{1, *}$, A. Olabi ${ }^{3}$}

1. Institute of Engineering and Energy Technologies, School of Engineering and Computing, the University of the West of Scotland, Paisley PA1 2BE, UK.

2. School of Engineering and the Built Environment, Birmingham City University, Birmingham B5 5JU, UK.

3. Chair in Mechanical Engineering and Design, Aston University, School of Engineering and Applied Science, Aston Triangle, Birmingham, B4 7ET, UK

Abstract:

The process of extracting lipids from high-moisture Scenedesmus quadricauda microalgae biomass disrupted with microwave was examined. The study showed that microwave pretreatment is effective in algae cell rupture while microwave power was found to be a significant factor to enhance the degree of cell disruption. Though microwave pre-treatment time had some effect, the degree of cell rupture seemed to decrease after a certain pretreatment time. The total lipid from Scenedesmus quadricauda sp. were extracted using a mixture methanol and sulphuric acid as an organic solvent. In addition, it was discovered that microwave pre-treatment enhances the disruption of microalgae cells to attain a high level of lipid yields. Optimal lipid yield obtained in this study was $49 \%$ at power $600 \mathrm{~W}$, heating time of $8 \mathrm{~min}$ and extraction time of $3.5 \mathrm{~h}$.

Keywords: microalgae, lipid extraction, microwave pre-treatment, modelling, optimization, biodiesel

\footnotetext{
*Corresponding author. E-mail address: cristina.rodriguez@uws.ac.uk
} 


\section{Introduction:}

Though algae biofuels are not yet commercial, their economic outlook is promising [1-4]. The obsolete development of lipid extraction from microalgae cells often involves the consumption of a large amount of energy because of microalgae dewatering process [5]. Using microalgae biomass a potential substitute fuel production has increased globally [6], as microalgae represent a renewable energy resource which captures atmospheric carbon dioxide (CO2) photosynthetically and produces lipids that can be converted to biodiesel [79]. However, large-scale production of microalgae biomass and energy efficiency is yet to become a sustainable reality.

Fundamental issues are obviously high lipid productivity, energy efficient downstream processes and energy balance in the case of dry route lipid extraction is not positive. According to K. Sander and G. Murthy [10], the minimum net energy input is 3982 MJ for 24 $\mathrm{kg}$ of biomass with a lipid content between 30 and $40 \%$ (w/w), necessary for the production of $1000 \mathrm{MJ}$ microalgae biodiesel. However, a natural gas dryer requires $3556 \mathrm{~kJ} / \mathrm{kg}$ water removed which represents $89 \%$ of the total energy input. Generally, life-cycle assessment (LCA) studies of biodiesel from microalgae pointed out that the step which requires the most energy input is the biomass drying operation [11]. If the energy input is reduced with an improvement or removal of the drying operation, the net energy balance and cost would be positive [12].

Therefore, lipid recovery by wet extraction is of interest to reduce the energy demand. While Chisti et al. [13] confirm that biorefinery concepts are mainly used to valorise the whole biomass as a strategy to decrease the overall cost of the production, which must not exceed 0.25 dollar $/ \mathrm{kg}$ to compete for the petroleum. In addition, the energy applied during microwave pre-treatment has been noted to affect microalgae solubilisation, where Dai et al. [14] confirm that increasing microwave pre-treatment power from 400 to $1000 \mathrm{~W}$ increases microalgae lipid yield. Qv et al. [15] observed that increasing microwave power from 140 to $560 \mathrm{~W}$ increases lipid extraction efficiency. However, most previous studies also reported that further increase in microwave power $700 \mathrm{~W}$ decreases microalgae lipid yield. A study conducted by Biller et al. [16] confirms that increasing the microwave power from 25 - 61 Wh/g resulted in increased lipid yield from Nannochloropsis sp. biomass from 1.6 to $10 \%$. 
Passos et al. [17], noted that increasing the microwave energy from 300-900 W increases microalgae biomass solubilisation. The energy consumed during microwave irradiation pretreatment depends on the temperature and duration of cell disruption. Some previous studies have studied the effects of energy consumed during microalgae cell disintegration on lipid yield. Balasubramanian et al [18], arrive at a conclusion that $76-77 \%$ of the oil from dried Scenedesmus obliquus sp. was achievable using microwave radiation with an energy consumption of $60 \mathrm{Wh} / \mathrm{g}$. The high moisture of microalgae growth medium of $99.9 \% \mathrm{w} / \mathrm{w}$ has increasingly become a barrier for the entire production process [19]. Lee et al. [20] confirm that disrupting $100 \mathrm{ml}$ of microalgae cell suspension by microwave with an energy input of $700 \mathrm{~W}$ for $5 \mathrm{~min}$, the energy consumed is equivalent to $420 \mathrm{MJ}$ kg1 of dry algal mass. In addition, physical and chemical harvesting techniques such as sedimentation, flocculation, freeze dry and centrifugation can only decrease the quantity of moisture close to 90\% (w/w), where further removal of moisture can only be achieved by drying process [19]. The dry process is not energy efficient and cost-effective, as this increases the possibility of making the entire production process not economically efficient. Also, the size of microalgae strains [21], and the existence of rigid cell wall that requires being ruptured [22-24] to enhance lipid extraction, still has significant challenges in microalgae production process. However, the development of production processes and the conversion of algal biomass to biodiesel to achieve cost efficiencies that rival petroleum-based fuels is an ongoing challenge that demands an in-depth understanding of both algal biology and process engineering [2527]. Also, the high-quality of algal species is essential in determining the amount of lipid produced, an efficient effective method of lipid extraction is of much importance towards commercial biofuel production [28,29]. Subsequently, for lipid extraction process to be successful using microalgae biomass, there is a need for an efficient cell disruption phase that will enhance lipid production. Previous studies have used both mechanical and nonmechanical pre-treatment for microalgae cell rupture[30]. A study conducted by Halim et al. [22] used direct counting and average colony diameter methods to determine the disruption efficacy of many treatments to lyse Chlorococcum sp., these includes; high pressure homogenizer (73.8\%), sulphuric acid treatment (33.2\%), bead beating (33.2\%), and ultrasonic (4.5\%). They concluded that high-pressure homogenizer has the highest percentage of cell rupture but is not energy efficient. Lee et al. [31] affirms that bead beating effectively disrupts algae cell more efficiently. A study by Chisti et al. [32] evaluated the use of 
mechanical disruption technique using bead beating, HPH with liquid shear, ultrasonic and freeze press, and they concluded that cell rupture is dependent on the microorganism. The outstanding problem about mechanical cell rupture is that they are not energy efficient. For this reason, previous studies have demonstrated that microwave pre-treatment has been effectively used in cell disruption of microalgae cell walls [18,33-35] to enhance lipid production. This method has been applied in numerous areas which includes: chemical synthesis, solvent extraction, and solid state reaction [36]. Other applications includes; catalytic and non-catalytic transesterification processes [37], pyrolysis and hydrothermal liquefaction of microalgae for biofuel production[38].

Other studies that applied microwave irradiation pre-treatment on different biomass material to produce biogas includes [17,39-42]. In addition, Refaat et al. [43], applied microwave pretreatment using sunflower and achieved 5.96\% of lipid, Chen et al. [44] uses waste cooking oil and produces 38.31\% of lipid and Cheng et al. [45] also applied microwave pre-treatment using Nannochloropsis Oceanica sp. and recorded 38.46\% of lipid yields. Balasubramanian et al. [18] added that increasing reaction time from 10 and 20 min using microwave pretreatment on Scenesdesmus obliquus sp. enhances lipid yield from 10\% to 22\%. Thus, microwave energy can play an important role in microalgae cell pre-treatment to enhance biofuel production. Also, microwave time plays a significant role during microalgae cell disruption, which determines the recovery efficiency of the lipids present in microalgae biomass [46]. Menendez et al. [47] observed the effect of increasing microwave pretreatment time from 10 -20 mins using Nannochloropsis gaditana and achieved a lipid yield of 29-40\%. Balasubramanian et al. [18] affirmed that increasing the microwave heating time from 10-20 mins resulted in an increased in lipid yield from 10-22\% using Scendesmus obliquss after pre-treatment. while Dai et al. [14] concluded that that increased in microwave extraction time from 10 to 40 min resulted in increased microalgae lipid recovery 14 to $18 \%$. However, all the research works mentioned above used dry and different biomass material for lipid production, at present no study has used microwave pre-treatment on Scenesdemus quadricauda to enhance lipid extraction. Considering the energy and equipment cost related to drying and dewatering microalgae cells, it would be cost-effective if wet microalgae cells can be used directly for biofuel production after pre-treatment. Also, the extraction of lipids from dried microalgae cells incurs a large amount of energy during dewatering process. To 
improve this situation, some research studies has focused on an alternative approach for the lipid extraction using wet microalgae, as discussed in [31,36,48-50].

Therefore, the objectives of the study include; (a) Modelling and optimization microwave pre-treatment parameters using response surface method after lipid extraction. (b) Performing numerical optimization to find the optimal combination of microwave power and time and reaction time that could maximize the \% of lipid yield, which is cost efficient as compared to other previous works.

\section{Materials and Methods:}

\subsection{Microalgae Cultivation}

Microalgae strain (Scenesdemus quadricauda) were purchase from Sciento-Manchester. 50 $\mathrm{ml}$ of each algae sample was kept in freezer at a temperature of 0 to $4^{\circ} \mathrm{C}$ to maintain a constant growth rate. The sample was cultured within the School of Engineering, University of the West Scotland (UK), in a 4-liter flask each after sterilization with distilled water at a temperature of $60^{\circ} \mathrm{C}$ for 4 hours and $3 \mathrm{~g}$ of the unicellular culture medium (K10) was bought from Sciento (Manchester, UK) was then added. The chemical composition of K10 unicellular medium includes; Sodium nitrate, Magnesium sulphate, Dipotassium hydrogen orthophosphate, Calcium chloride, Ammonium chloride and Trace elements with weight (\%) of 62, 16, 15, 4,3 and $<1$ respectively). The flask was vigorously hand shake twice each day to enhance appropriate circulation of the nutrients during cultivation period. Room temperature of $15^{\circ} \mathrm{C}$ to $25^{\circ} \mathrm{C}$ was maintained throughout the culture period. A spectrophotometer at a wave length of $600 \mathrm{~nm}$ was used to determine the initial cell concentration before and at the end of culture period; which has the value of $1.815 \times 10^{8}$ cell $/ \mathrm{ml}$ and $7.7637 \times 10^{16} \mathrm{cell} / \mathrm{ml}$. After 20 days, the cultivation process was completed.

\subsection{Microwave Pre-treatment}

$500 \mathrm{ml}$ sample of the standard culture were subjected to microwave pre-treatment using a round bottom open glass. The samples were pre-treated at different microwave power of $600 \mathrm{~W}, 390 \mathrm{~W}$ and $180 \mathrm{~W}$ and time between 8,5 and 2 minutes, until each pre-treatment phase is completed. The pre-treatment was performed using a stainless-steel microwave oven 
(Bosch BOSHMT75M451B, $800 \mathrm{~W}, 5$ power levels and 60 min timer). All the experiments were run in duplicate and the average results are presented in this paper.

\subsection{Extraction Procedure:}

Initially, $500 \mathrm{ml}$ of wet algae sample were pre-treated using a conventional microwave according to pre-determine microwave power and time. The two parameters were selected based on previous research studies to give a distinct percentage of cell disruption [19]. A $500 \mathrm{ml}$ of each pre-treated sample were placed in a flask by adding $500 \mathrm{~cm}^{3}$ of methanol and $10 \mathrm{ml}$ of sulphuric acid. Anti-bump granules were added to the flask and reflux at each selected time of reaction. After the refluxing, the sample was extracted using 3 x $150 \mathrm{ml}$ and washed with 5\% of sodium bicarbonate solution. The reflux process was repeated for 14 different experimental conditions with different extraction times (3, 3.5 and 4 h respectively). The solvent used was evaporated using a steam bath to obtain the liquid extract.

\subsection{Design of Experiments:}

The experimental modelling was designed for 3 input parameters with three levels. Microwave power varies from 180 to $600 \mathrm{~W}$, microwave time between 2 to $8 \mathrm{~min}$ and reaction time between 3 to 4 hrs. The output response was \% of lipid recovered after each extraction time. Both the process parameter and output response results are indicated in Table 2. A Box-Behken Design with three factors was selected for design of experiments. Fourteen experiments were determined by DOE, statistical analysis as well as the provision of extensive graphs that showcase the relationship between the input parameters and the output responses [51,52]. The process parameters selected was microwave power, time and extraction time. The response was the \% of lipid produced per each $500-\mathrm{ml}$ sample produced. RSM is considered by high adherence to the experimental data describing the reality of what was studied [53]. Moreover, RSM methods are able to exhibit the factor contributions from the coefficients in the regression model to identify the insignificant factors and thereby, reduce the complexity of the problem[54]. Table 1 summarises the three levels and ranges of process parameters used in the design, while Table 2 shows the experimental conditions and amount of lipid recovered using Box-Behken design.

Table 1. Process variables and their units, levels used in the Experimental Design. 


\begin{tabular}{lcccc}
\hline \multirow{2}{*}{ Variable } & Units & \multicolumn{3}{c}{ Levels } \\
\cline { 3 - 5 } & & -1 & 0 & 1 \\
\hline Microwave Power & $\mathrm{W}$ & 180 & 390 & 600 \\
Time & $\min$ & 2 & 5 & 8 \\
Extraction Time & $\mathrm{h}$ & 3 & 3.5 & 4 \\
\hline
\end{tabular}

178

179

Table 2. Box-Behken Design experimental design matrix showing the effects of process parameter on the output response (\% recovered lipids).

\begin{tabular}{|c|c|c|c|c|}
\hline \multirow[b]{3}{*}{ Run } & \multicolumn{3}{|c|}{ Input } & \multirow{2}{*}{$\begin{array}{c}\text { Results } \\
\text { Response }\end{array}$} \\
\hline & Factor 1 & Factor 2 & Factor 3 & \\
\hline & A: Power & B: Heating Times & C: Extraction Time & \% Recovered lipid \\
\hline & $\mathrm{W}$ & $\min$ & $\mathrm{h}$ & $\%$ \\
\hline 1 & 180 & 5 & 3 & 14.01 \\
\hline 2 & 180 & 2 & 3.5 & 14.44 \\
\hline 3 & 180 & 8 & 3.5 & 10.83 \\
\hline 4 & 180 & 5 & 4 & 18.86 \\
\hline 5 & 390 & 2 & 3 & 18.87 \\
\hline 6 & 390 & 8 & 3 & 18.87 \\
\hline 7 & 390 & 5 & 3.5 & 32.43 \\
\hline 8 & 390 & 5 & 3.5 & 11.68 \\
\hline 9 & 390 & 5 & 3.5 & 25.46 \\
\hline 10 & 390 & 2 & 4 & 14.44 \\
\hline 11 & 390 & 8 & 4 & 37.84 \\
\hline 12 & 600 & 5 & 3 & 32.43 \\
\hline 13 & 600 & 2 & 3.5 & 18.69 \\
\hline 14 & 600 & 8 & 3.5 & 48.65 \\
\hline 15 & 600 & 5 & 4 & 25.45 \\
\hline
\end{tabular}

181

$182 \quad 2.5$. Analysis method 
The experimental data analysis was performed using Design Expert software version 10, which predicts the optimal condition. The quadratic polynomial model used for response surface regression procedure for this work is shown in Eq 1. Also, RSM consist of a group of mathematical model and statistical techniques used in the development of an adequate functional relationship between a response of interest, y, and several associated control or input parameters denoted by $\times_{1} \ldots \ldots \times_{2} \ldots \ldots \ldots \times_{k}$. Hence, the second order polynomial equation is shown in Eq. (1), this is used to describe the true functional relationship between the input parameters and the output response.

$$
Y=b_{0}+\sum b_{i} X_{I}+\sum b_{i i} X_{i i}^{2}+\sum b_{i j} X_{i} X_{j}
$$

Where $\mathrm{Y}$ is the amount of lipid produced (Output Response), $\mathrm{b}_{\mathrm{o}}$ is the coefficient of the equation, $X_{i}$ and $X_{j}$ are the coded levels variables. $\mathrm{X}$ is the independent parameter and $\mathrm{b}_{\mathrm{i}}, \mathrm{b}_{\mathrm{ii}}$ and $b_{i j}$ are the intercept, linear quadratic and interaction regression coefficients respectively. The statistical significance of the model and the process parameters were assessed by analysis of variance (ANOVA), while the quality of the model was determined by the determination coefficient $\left(R^{2}\right)$. The ANOVA table for the response surface quadratic model on $\%$ of recovered lipid is shown in Table 3.

(1)

(1)

(1)

2

(1)




\begin{tabular}{lrrrrr}
\hline Source & Sum of Squares & df & Mean Square & F- Value & p-value \\
& & & & & \\
\hline Model & 1344.77 & 7 & 192.11 & 4.54 & 0.0320 \\
A-mw power & 562.47 & 1 & 562.47 & 13.28 & 0.0082 \\
B-mw time & 309.38 & 1 & 309.38 & 7.31 & 0.0305 \\
C-reaction time & 19.25 & 1 & 19.25 & 0.45 & 0.5218 \\
AB & 281.74 & 1 & 281.74 & 6.65 & 0.0365 \\
AC & 34.99 & 1 & 34.99 & 0.83 & 0.3936 \\
BC & 136.89 & 1 & 136.89 & 3.23 & 0.1152 \\
$\mathrm{~A}^{2}$ & 0.055 & 1 & 0.055 & $1.3 \cdot 10^{-3}$ & 0.9722 \\
Residual & 296.45 & 7 & 42.35 & & \\
\multicolumn{1}{c}{ Lack of Fit } & 73.44 & 5 & 14.69 & 0.13 & 0.9695 \\
\multicolumn{1}{c}{ Pure Error } & 223.01 & 2 & 111.51 & & \\
Cor Total & 1641.22 & 14 & & & \\
\hline $\mathrm{R}^{2}=0.8194$ & Pred $\mathrm{R}^{2}=0.4903$ & Adj $\mathrm{R}^{2}=0.6387$ & & & \\
\hline
\end{tabular}

209

210 3. Results and Discussion:

211 3.1. Development of a regression model.

212 The 15-experimental results for Seneesdemus quadricauda are shown in Table 2. The

213 percentage of recovered lipid ranged from $14.01 \%$ to $48.65 \%$. The final mathematical model

214 associated with the response in terms of actual factors is shown in Eq. 2, while the ANOVA

215 test is indicated in Table 3.

$216 \% R L=42.20+0.07 A-16.77 B-5.41 C+0.01 A B-0.03 A C+3.90 B C+2.75 \times 10^{-6} A^{2}$

217 where RL: Recovered lipids A- microwave power, B-microwave time, C-reaction time as

218 indicated in Table 3.

219 A variation less than 0.2 between adjusted- $\mathrm{R}^{2}=0.6387$ and Predicted- $\mathrm{R}^{2}=0.4903$, indicated

220 that the adopted model is adequate. The entire adequacy measures are less than 0.2 , which are

221 in reasonable agreement and significantly shows adequate model [55,56], because the

222 statistical analysis as considered by the Design Expert, it indicates that any value equal less 
than 0.2 are considered when determining the adequacy measures of adjusted- $\mathrm{R}^{2}$ and Predicted- $\mathrm{R}^{2}$. Where lack of Fit F-value of 0.13 implied that lack of fit was not significant relative to the pure error (Table 2), this was tested to know if the Prob $>F$ of the lack of fit exceeds the level of significance as shown in table 3. Also, in Response surface methodology (p-value) of lack fit if $>0.05$ (not significant) signifies that the model fits well and there is no significant effect on parameters on output response. Hence, the term adjusted R-squared as indicated in the ANOVA table 3. compares the explanatory power of regression models that contain different numbers of predictors, also it is a modified version of R-squared that has been adjusted for the number of predictors in the model. They increase only if the new term improves the model more than would be expected by chance. While predicted R-squared indicates how good a regression model predicts response for new observation, it determines when the model fits the original data but less capable of providing valid predictions for new observation.

\subsection{Effects of interaction between parameters using response surface methodology plots.}

The response surface plot (Fig 1) obtained from the model shows the effect of microwave power and reaction time in the \% of recovered lipids. For a fixed microwave time of $8 \mathrm{~min}$ and extraction time $4 \mathrm{hrs}$, increasing the power from 180 to $600 \mathrm{~W}$, the $\%$ of lipid-recovered increases by $150 \%$ respectively. For a maximum pre-treatment conditions of $600 \mathrm{~W}$ and $8 \mathrm{~min}$, the \% of recovered lipids increased by $25 \%$ by increasing the reaction time from 3 to $4 \mathrm{~h}$. The effect of pre-treatment time is shown in Fig 2, for a fixed reaction time of $3.5 \mathrm{hrs}$ and a microwave power of $600 \mathrm{~W}$, an increase of $200 \%$ is achieved by increasing the pretreatment time from 2 to $8 \mathrm{~min}$. If the microwave power is set at the lowest value of $180 \mathrm{~W}$, for the same variation in pre-treatment time, the increased obtained is $50 \%$. This shows that pre-treatment time has a higher effect on high microwave power. Combining high microwave power and time, the highest \% of recovered lipids are achieved. 
Design-Expert $₫$ Software

Factor Coding: Actual

Recovered lipids (\%)

- Design points above predicted value

- Design points below predicted value 48.65

10.83

$\mathrm{X} 1$ = A: mw power

$\mathrm{X} 2$ = C: reaction time

Actual Factor

$\mathrm{B}$ : $\mathrm{mw}$ time $=8$
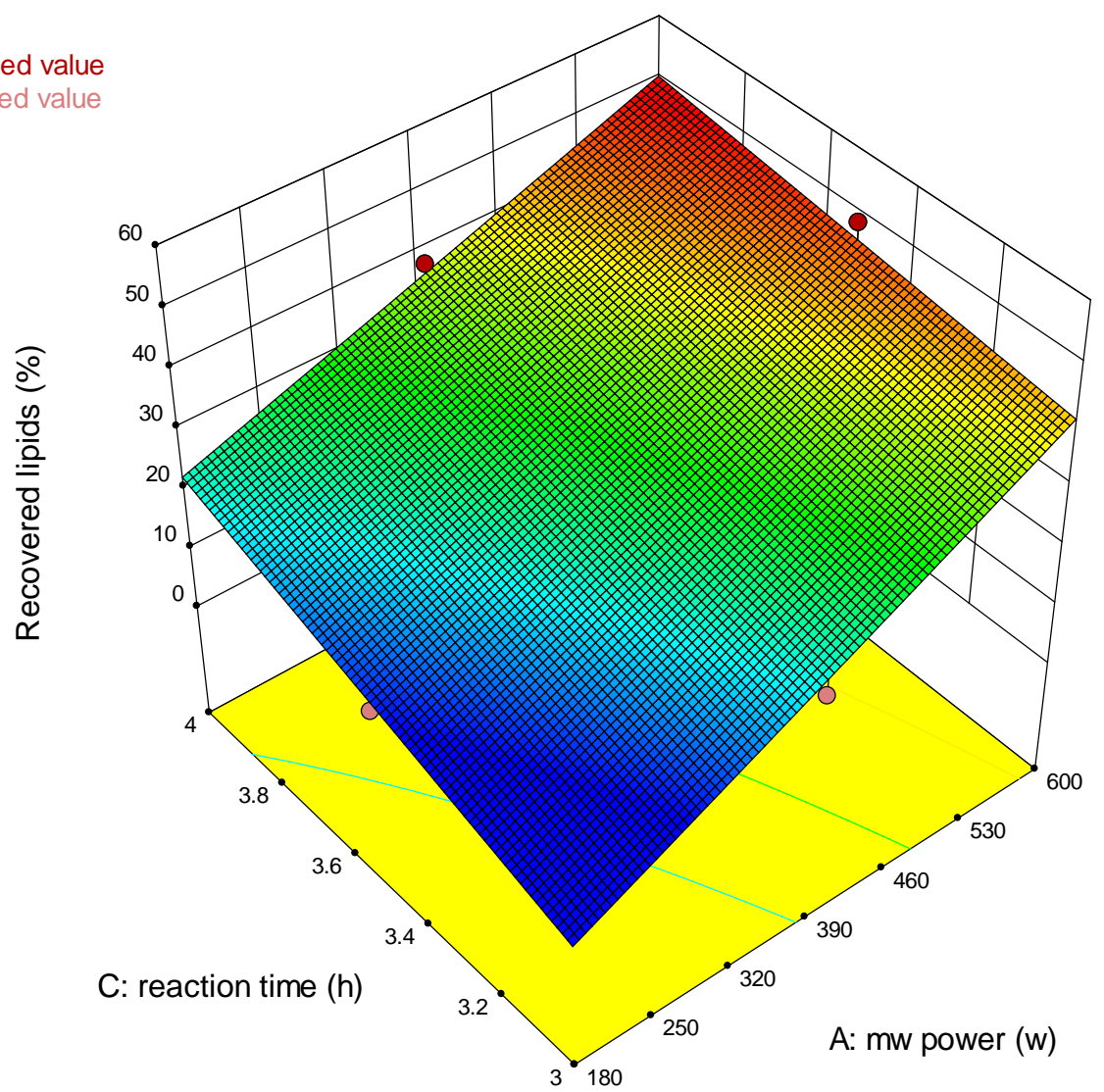

Figure 1. 3D response surface plot for \% of recovered lipid using microwave power and time. 
Design-Expert $®$ Software

Factor Coding: Actual

Recovered lipids (\%)

- Design points above predicted value

- Design points below predicted value

48.65

10.83

$\mathrm{X} 1$ = A: mw power

$\mathrm{X} 2=\mathrm{B}: \mathrm{mw}$ time

Actual Factor

C: reaction time $=3.5$

Figure 2. 3D response surface plot for \% of lipid recovered using microwave power and reaction time.

This proves that at a pre-treatment power of $600 \mathrm{~W}$ for $8 \mathrm{~min}$ the algae cells have been disrupted to enhance the lipid extraction. This fact correlates with the study conducted by [33,34,41,46,57-62] that using a high microwave power increases lipid efficiency. Though a decrease in both microwave power and time reduces lipid efficiency, this may be because of some of the algae cells remain undisrupted which inhibit the rate of lipid extraction. The reaction time has a significant effect on the \% of lipid recovered. Generally, extended pretreatment time provides an enhanced exposure of microalgae mixture to microwave effect, which improves a better yield of lipid. Decreasing the exposure time seems not to provide enough cell-disruption degree to achieve high \% of recovered lipids. For this reason, one can assume that a low pre-treatment time, the algae cell remains intact which may lead to a low lipid yield (Table 2). The reaction time around 3.5 to $4 \mathrm{~h}$ and heating time of $8 \mathrm{~min}$ seems to 
266 be satisfactory for complete extraction under microwave pre-treatment. Thus, the efficiency

267 of lipid extraction increased due to high cell-disruption after microwave pre-treatment. Also,

268 an import fact to note for future research is that more work should focus on the

269 effects/benefits of harvesting microalgae cells as summarized by the [63]. In addition, few

270 reviews studied the effect of microwave pre-treatment to enhance lipid extraction efficiency

271 for biofuel production. Cheng et al. [45] observed the effect of pre-treating Nannochloropsis

272 Oceania sp. using microwave irradiation at a frequency of $245 \mathrm{MHz}$ and a power increase

273 from $635-1022 \mathrm{~W}$ for 15 mins pre-treatment. It was recorded a 38.46\% of lipid yields. This

274 present shows that lipid production was achieved at a higher microwave energy and pre-

275 treatment time. This result agreed well with [14,20,64], who realized that increasing in

276 microwave power have a significant effect on the production of lipid using different

277 microalgae cells. A different study conducted by Cheng et al. [65] noticed the effect of

278 microwave pre-treatment at a frequency of $2.45 \mathrm{GHz}$, a reduction in power from $600-500 \mathrm{~W}$

279 for 5-60 mins on (Chlorella pyrenoidosa). The author realized a 15\% of lipid yield after

280 decreasing the microwave power to $500 \mathrm{~W}$ with an increase in pre-treatment time. A similar

281 result obtained by $[14,47,66]$ agrees that increasing microwave pre-treatment time increases

282 lipid yield production. At the end of the microwave pre-treatments, the lipid yield was 10-

$28322 \%, 29-40 \%$ and 14-18\% respectively. In this research work, a short microwave pre-

284 treatment time of 8 mins power of $600 \mathrm{~W}$ increase the lipid extraction rate to $49 \%$ using wet

285 microalgae cell (Scenedesmus quadricauda sp.) which is higher than all the above results as 286 discussed. 
Design-Expert $®$ Software

Factor Coding: Actual

Recovered lipids (\%)

Actual Factors

A: mw power $=390$

B: mw time $=5.08108$

C: reaction time $=3.5$

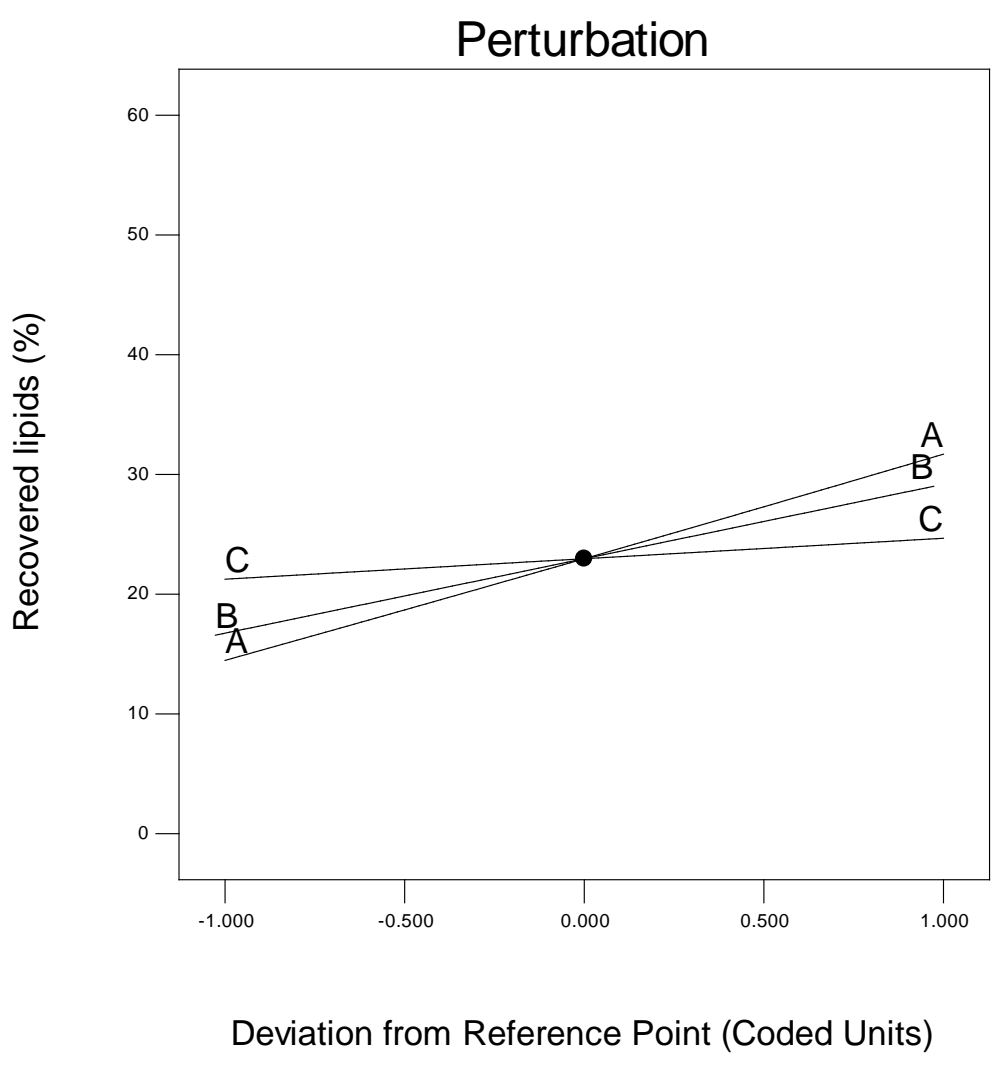

Figure 3. Perturbation plot for \% of recovered lipid.

The perturbation plot in Fig. 3 clearly shows how \% of recovered lipid is affected by the input parameters microwave power and time and reaction time. Increasing the microwave power and heating time, the \% of lipid recovered will increase linearly. Reaction time has little effect on lipid recovery as shown by the quasi-horizontal line $\mathrm{C}$ in Fig 3.

\subsection{Optimization of lipid recovered}

With respect to the model as represented in in Eq. 2, above, which systematically gives a concise description of the effects of input parameters to the output response (\% of lipid recovered), optimization was performed using Design Expert software version 10. Hence, optimization principle is based on the combination of final product maximization (productivity). In this case, optimization simply means maximizing operational efficiency to improve output efficiency. The aim of the optimization is to find the optimal combination of microwave power and times that could maximize the \% yield of lipid yield. The \% of lipid 
302

303

304

305

306

307

308

309

recovered was maximized with level 5 and microwave power was minimized with level 3. An optimum \% of recovered lipid of 41.94 was obtained at microwave time of $8 \mathrm{~min}$, microwave power of $473 \mathrm{~W}$ and reaction time of $4 \mathrm{~h}$. The optimization plots (Fig 4 and 5) gives a concise description of the optimal process parameters by means of visual observation. The yellow region in the optimization plot signifies the values that meet the planned standards truly established by the curves agree with the standard of the optimization criteria. The plots clearly established that the optimum conditions for a maximized \% of recovered lipids are above $350 \mathrm{~W}$ and 4 min of microwave pre-treatment.
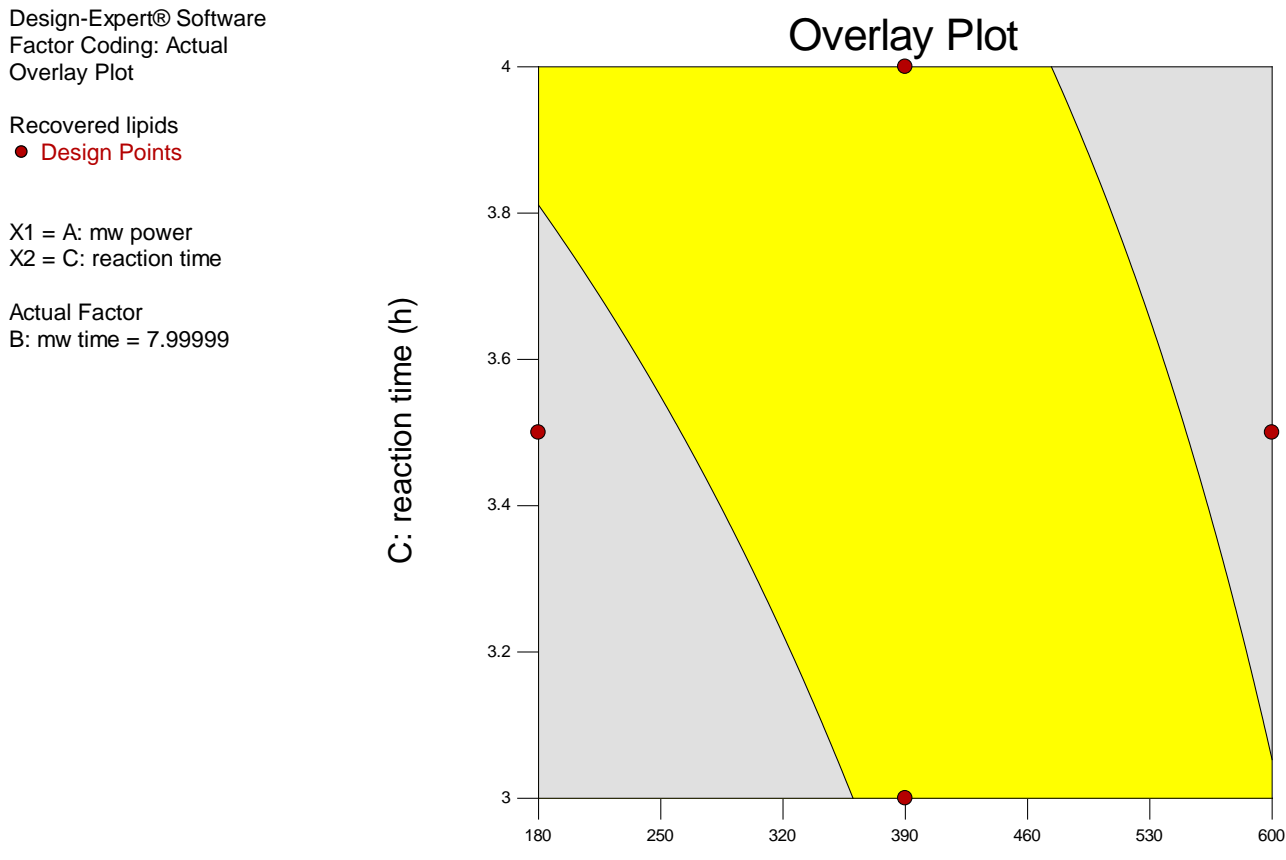

A: mw power $(w)$

310

Figure 4. Graphical optimization showing the effect of reaction time and microwave power. 
Design-Expert $₫$ Software

Factor Coding: Actual

Overlay Plot

Recovered lipids

- Design Points

$\mathrm{X} 1$ = A: mw power

$\mathrm{X} 2=\mathrm{B}: \mathrm{mw}$ time

Actual Factor

C: reaction time $=4$

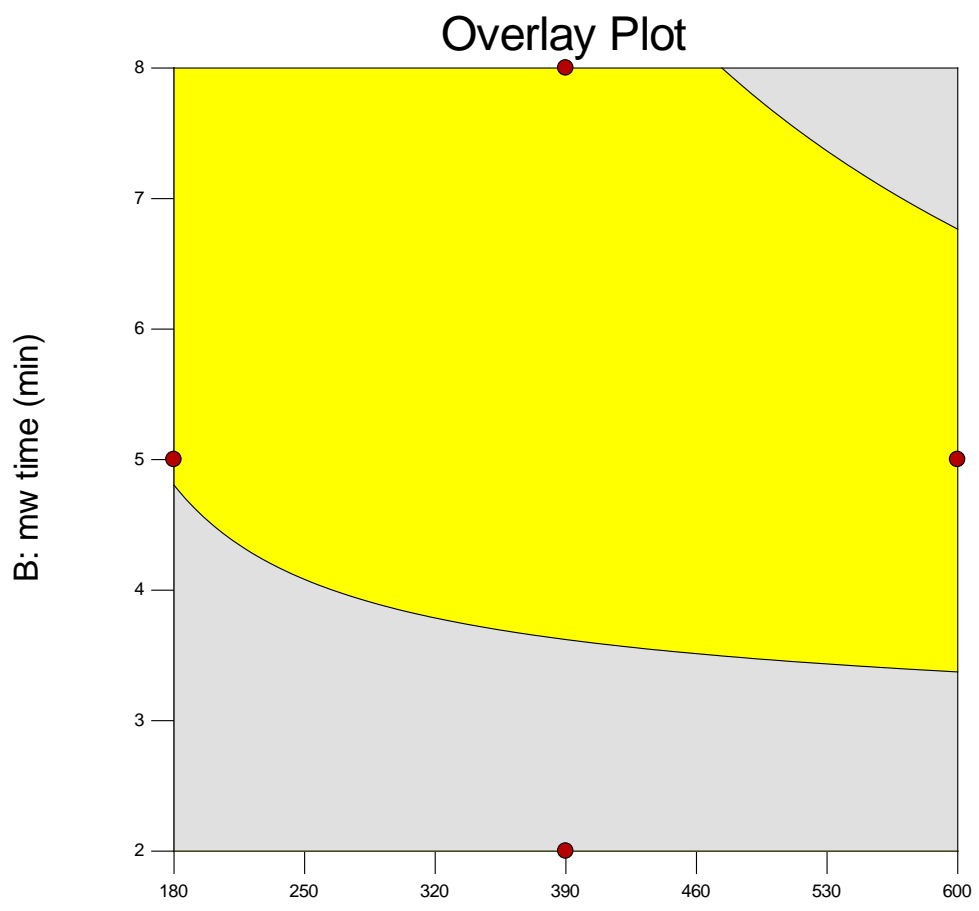

A: mw power (w)

Figure 5. Graphical optimization showing the effect of microwave time and power.

315 To confirm the viability of this method, the optimum point of the RSM (section 3.3) was compared with a commercial sample of biodiesel from a petrol station (Biodiesel 80:20 mix).

\begin{tabular}{lcc}
\hline \multicolumn{1}{c}{ Analytes } & Commercial Sample $(\mu \mathrm{g} / \mathrm{ml})$ & Optimum sample $(\mu \mathrm{g} / \mathrm{ml})$ \\
\hline methyl myristate - C14 & 0.00 & 154.73 \\
methyl palmitate - C16 & 110.50 & 268.12 \\
methyl stearate - C18 & 102.23 & 27.92 \\
methyl linoleate - C18:2 & 171.00 & 8.38 \\
methyl arachidate - C20 & 117.45 & 10.21 \\
methyl eicosate - C20:1 & 515.20 & 21.22 \\
methyl eicosadienoate - C20:2 & 359.45 & 14.46 \\
methyl erucate - C22:1 & 13.11 & 4.91 \\
\hline
\end{tabular}


318 The result clearly established the presence of individual FAME's that are required to accurately identify the sample as viable for biofuel production. From the table 4, the concentration of FAME sample was found to be $268.12 \mu \mathrm{g} / \mathrm{ml}$ higher in methyl palmitate C16 as when compared with the commercial biodiesel (80:20 mix), methyl myristate - C14 was not present in the commercial biodiesel as it was present in FAME extract with a concentration of $154.73 \mu \mathrm{g} / \mathrm{ml}$. It can be concluded that this method has a significant contribution towards microalgae biofuel industry.

\section{Conclusion}

Pre-treating algae biomass with microwave for $600 \mathrm{~W}$, from 2 to 8 min enhances the \% of recovered lipid to $49 \%$. In addition, the reaction time from 3.5 to 4 hrs seems to be satisfactory for complete extraction under microwave pre-treatment for lipid extraction efficiency. An optimization study was accomplished to reduce the operating cost and pretreatment time to maximize the lipid production efficiency. The basic aim is to maximize the $\%$ of lipid production while minimizing the microwave pre-treatment time. An optimum \% lipid yield of 41.94 was obtained at a microwave time $8 \mathrm{~min}$, a reaction time of $4 \mathrm{hrs}$ and power $473 \mathrm{~W}$. The highest lipid yield reported after pre-treatment as when compared with results obtained from literature was reviewed in this research study. As cheng et al. [45] reported a lipid extraction using a dry algae cell to achieve $38.46 \%$ lipid after pre-treatment, while Menendez et al. [47] achieve 29-40\% of lipids by increasing the time to 20 mins. Other results as reported in the literature above has a low value of lipid yield even with a high pretreatment time as compared to this present study. This idea concludes the fact that using a wet microalgae biomass shows a desirable value and lipid profile as a potential feedstock for biodiesel production.

\section{References:}

[1] Y. Chisti, J. Yan, Energy from algae: Current status and future trends. Algal biofuels A status report, Appl. Energy. 88 (2011) 3277-3279. doi:10.1016/j.apenergy.2011.04.038.

[2] C. Rodriguez, A. Alaswad, Z. El-Hassan, A.G. Olabi, Improvement of methane production from P. canaliculata through mechanical pretreatment, Renew. Energy. 119 (2017) 73-78. doi:10.1016/j.renene.2017.12.025. 
[3] A.G. Olabi, State of the art on renewable and sustainable energy, Energy. 61 (2013) 25. doi:10.1016/j.energy.2013.10.013.

[4] C. Rodriguez, A. Alaswad, Z. El-Hassan, A. G. Olabi, Waste paper and macroalgae co-digestion effect on methane production, Energy. 154 (2018) 119-125. doi:10.1016/j.energy.2018.04.115.

[5] P.D. Patil, V.G. Gude, A. Mannarswamy, P. Cooke, N. Nirmalakhandan, P. Lammers, S. Deng, Comparison of direct transesterification of algal biomass under supercritical methanol and microwave irradiation conditions, Fuel. 97 (2012) 822-831. doi:10.1016/j.fuel.2012.02.037.

[6] M. Balat, H. Balat, Progress in biodiesel processing, Appl. Energy. 87 (2010) 18151835. doi:10.1016/j.apenergy.2010.01.012.

[7] C. Rodriguez, A. Alaswad, J. Mooney, T. Prescott, A.G. Olabi, Pre-treatment techniques used for anaerobic digestion of algae, Fuel Process. Technol. 138 (2015) 765-779. doi:10.1016/j.fuproc.2015.06.027.

[8] T. Wilberforce, Z. El-Hassan, F.N. Khatib, A. Al Makky, J. Mooney, A. Barouaji, J.G. Carton, A.-G. Olabi, Development of Bi-polar plate design of PEM fuel cell using CFD techniques, Int. J. Hydrogen Energy. 42 (2017) 25663-25685. doi:10.1016/J.IJHYDENE.2017.08.093.

[9] T. Wilberforce, Z. El-Hassan, F.N. Khatib, A. Al Makky, A. Baroutaji, J.G. Carton, A.G. Olabi, Developments of electric cars and fuel cell hydrogen electric cars, Int. J. Hydrogen Energy. 42 (2017) 25695-25734. doi:10.1016/J.IJHYDENE.2017.07.054.

[10] K. Sander, G.S. Murthy, Life cycle analysis of algae biodiesel, Int. J. Life Cycle Assess. 15 (2010) 704-714. doi:10.1007/s11367-010-0194-1.

[11] E.P. Bennion, D.M. Ginosar, J. Moses, F. Agblevor, J.C. Quinn, Lifecycle assessment of microalgae to biofuel: Comparison of thermochemical processing pathways, Appl. Energy. 154 (2015) 1062-1071. doi:10.1016/j.apenergy.2014.12.009.

[12] M.K. Lam, K.T. Lee, Microalgae biofuels: A critical review of issues, problems and the way forward, Biotechnol. Adv. 30 (2012) 673-690.

doi:10.1016/j.biotechadv.2011.11.008.

[13] Y. Chisti, Constraints to commercialization of algal fuels, J. Biotechnol. 167 (2013) 201-214. doi:10.1016/j.jbiotec.2013.07.020.

[14] Y.-M. Dai, K.-T. Chen, C.-C. Chen, Study of the microwave lipid extraction from microalgae for biodiesel production, Chem. Eng. J. 250 (2014) 267-273. doi:10.1016/j.cej.2014.04.031.

[15] X. Qv, Q. Zhou, J. Jiang, Ultrasound-enhanced and microwave-assisted extraction of lipid from Dunaliella tertiolecta and fatty acid profile analysis, J. Sep. Sci. 37 (2014) 2991-2999. doi:10.1002/jssc.201400458.

[16] P. Biller, A.B. Ross, Hydrothermal processing of algal biomass for the production of biofuels and chemicals, Biofuels. 3 (2012) 603-623. doi:10.4155/bfs.12.42. 
[17] F. Passos, M. Solé, J. García, I. Ferrer, Biogas production from microalgae grown in wastewater: Effect of microwave pretreatment, Appl. Energy. 108 (2013) 168-175. doi:10.1016/j.apenergy.2013.02.042.

[18] S. Balasubramanian, J.D. Allen, A. Kanitkar, D. Boldor, Oil extraction from Scenedesmus obliquus using a continuous microwave system--design, optimization, and quality characterization., Bioresour. Technol. 102 (2011) 3396-403. doi:10.1016/j.biortech.2010.09.119.

[19] N. Samarasinghe, Effect of High Pressure Homogenization on Aqueous Phase Solvent Extraction of Lipids from Nannochloris Oculata Microalgae, J. Energy Nat. Resour. 1 (2012) 1. doi:10.11648/j.jenr.20120101.11.

[20] A.K. Lee, D.M. Lewis, P.J. Ashman, Disruption of microalgal cells for the extraction of lipids for biofuels: Processes and specific energy requirements, Biomass and Bioenergy. 46 (2012) 89-101. doi:10.1016/j.biombioe.2012.06.034.

[21] S.P. Slocombe, M. Ross, N. Thomas, S. McNeill, M.S. Stanley, A rapid and general method for measurement of protein in micro-algal biomass, Bioresour. Technol. 129 (2013) 51-57. doi:10.1016/j.biortech.2012.10.163.

[22] R. Halim, R. Harun, M.K. Danquah, P.A. Webley, Microalgal cell disruption for biofuel development, Appl. Energy. 91 (2012) 116-121. doi:10.1016/j.apenergy.2011.08.048.

[23] M. Wang, W. Yuan, X. Jiang, Y. Jing, Z. Wang, Disruption of microalgal cells using high-frequency focused ultrasound., Bioresour. Technol. 153 (2014) 315-21. doi:10.1016/j.biortech.2013.11.054.

[24] C. Onumaegbu, J. Mooney, A. Alaswad, A.G. Olabi, Pre-treatment methods for production of biofuel from microalgae biomass, Renew. Sustain. Energy Rev. 93 (2018) 16-26. doi:10.1016/j.rser.2018.04.015.

[25] S. a Scott, M.P. Davey, J.S. Dennis, I. Horst, C.J. Howe, D.J. Lea-Smith, A.G. Smith, Biodiesel from algae: Challenges and prospects, Curr. Opin. Biotechnol. 21 (2010) 277-286. doi:10.1016/j.copbio.2010.03.005.

[26] S. Abu-Ghosh, D. Fixler, Z. Dubinsky, D. Iluz, Energy-input analysis of the life-cycle of microalgal cultivation systems and best scenario for oil-rich biomass production, Appl. Energy. 154 (2015) 1082-1088. doi:10.1016/j.apenergy.2015.02.086.

[27] G. Chen, L. Zhao, Y. Qi, Enhancing the productivity of microalgae cultivated in wastewater toward biofuel production: A critical review, Appl. Energy. 137 (2015) 282-291. doi:10.1016/j.apenergy.2014.10.032.

[28] J.R. McMillan, I.A. Watson, M. Ali, W. Jaafar, Evaluation and comparison of algal cell disruption methods: Microwave, waterbath, blender, ultrasonic and laser treatment, Appl. Energy. 103 (2013) 128-134. doi:10.1016/j.apenergy.2012.09.020.

[29] C. Onumaegbu, A. Alaswad, C. Rodriguez, A. Olabi, Optimization of Pre-Treatment Process Parameters to Generate Biodiesel from Microalga, Energies. 11 (2018) 806. doi:10.3390/en11040806. 
[30] A. Clarke, T. Prescott, A. Khan, A.G. Olabi, Causes of breakage and disruption in a homogeniser, Appl. Energy. 87 (2010) 3680-3690.

doi:10.1016/j.apenergy.2010.05.007.

[31] J.-Y. Lee, C. Yoo, S.-Y. Jun, C.-Y. Ahn, H.-M. Oh, Comparison of several methods for effective lipid extraction from microalgae., Bioresour. Technol. 101 Suppl (2010) S75-7. doi:10.1016/j.biortech.2009.03.058.

[32] Y. Chisti, Biodiesel from microalgae beats bioethanol, Trends Biotechnol. 26 (2008) 126-131. doi:10.1016/j.tibtech.2007.12.002.

[33] C.L. Teo, A. Idris, Evaluation of direct transesterification of microalgae using microwave irradiation, Bioresour. Technol. 174 (2014) 281-285. doi:10.1016/j.biortech.2014.10.035.

[34] J. Gimbun, S. Ali, C.C.S.C. Kanwal, L.A. Shah, N.H.M.@ Ghazali, C.K. Cheng, S. Nurdin, Biodiesel Production from Rubber Seed Oil using Activated Cement Clinker as Catalyst, Procedia Eng. 53 (2013) 13-19. doi:10.1016/j.proeng.2013.02.003.

[35] B.H.J. Yap, S.A. Crawford, G.J. Dumsday, P.J. Scales, G.J.O. Martin, A mechanistic study of algal cell disruption and its effect on lipid recovery by solvent extraction, Algal Res. 5 (2014) 112-120. doi:10.1016/j.algal.2014.07.001.

[36] Y. Cui, Y. Liang, Direct transesterification of wet Cryptococcus curvatus cells to biodiesel through use of microwave irradiation, Appl. Energy. 119 (2014) 438-444. doi:10.1016/j.apenergy.2014.01.016.

[37] D.T. Tran, J.S. Chang, D.J. Lee, Recent insights into continuous-flow biodiesel production via catalytic and non-catalytic transesterification processes, Appl. Energy. 185 (2017) 376-409. doi:10.1016/j.apenergy.2016.11.006.

[38] D. Chiaramonti, M. Prussi, M. Buffi, A. Maria, L. Pari, Review and experimental study on pyrolysis and hydrothermal liquefaction of microalgae for biofuel production, Appl. Energy. (2016) 1-10. doi:10.1016/j.apenergy.2015.12.001.

[39] Z. Sapci, The effect of microwave pretreatment on biogas production from agricultural straws., Bioresour. Technol. 128 (2013) 487-94. doi:10.1016/j.biortech.2012.09.094.

[40] J.R. Miranda, P.C. Passarinho, L. Gouveia, Pre-treatment optimization of Scenedesmus obliquus microalga for bioethanol production, Bioresour. Technol. 104 (2012) 342-348. doi:10.1016/j.biortech.2011.10.059.

[41] L. Mgudu, E. Muzenda, J. Kabuba, M. Belaid, Microwave - Assisted Extraction of Castor Oil, 2028 (2012) 71-73.

[42] M. Kuglarz, D. Karakashev, I. Angelidaki, Microwave and thermal pretreatment as methods for increasing the biogas potential of secondary sludge from municipal wastewater treatment plants, Bioresour. Technol. 134 (2013) 290-297. doi:10.1016/j.biortech.2013.02.001.

[43] a. a. Refaat, S.T.E. Sheltawy, K.U. Sadek, Optimum reaction time, performance and exhaust emissions of biodiesel produced by microwave irradiation, Environ. Sci. Technol. 5 (2008) 315-322. doi:10.1007/BF03326026. 
[44] K.-S. Chen, Y.-C. Lin, K.-H. Hsu, H.-K. Wang, Improving biodiesel yields from waste cooking oil by using sodium methoxide and a microwave heating system, Energy. 38 (2012) 151-156. doi:10.1016/j.energy.2011.12.020.

[45] J. Cheng, R. Huang, T. Yu, T. Li, J. Zhou, K. Cen, Biodiesel production from lipids in wet microalgae with microwave irradiation and bio-crude production from algal residue through hydrothermal liquefaction, Bioresour. Technol. 151 (2014) 415-418. doi:10.1016/j.biortech.2013.10.033.

[46] P.D. Patil, V.G. Gude, A. Mannarswamy, P. Cooke, S. Munson-McGee, N. Nirmalakhandan, P. Lammers, S. Deng, Optimization of microwave-assisted transesterification of dry algal biomass using response surface methodology., Bioresour. Technol. 102 (2011) 1399-405. doi:10.1016/j.biortech.2010.09.046.

[47] L. Mendez, A. Mahdy, M. Demuez, M. Ballesteros, C. González-Fernández, Effect of high pressure thermal pretreatment on Chlorella vulgaris biomass: Organic matter solubilisation and biochemical methane potential, Fuel. 117 (2014) 674-679. doi:10.1016/j.fuel.2013.09.032.

[48] J. Cheng, R. Huang, T. Li, J. Zhou, K. Cen, Biodiesel from wet microalgae: Extraction with hexane after the microwave-assisted transesterification of lipids, Bioresour. Technol. 170 (2014) 69-75. doi:10.1016/j.biortech.2014.07.089.

[49] Y. Pan, M.A. Alam, Z. Wang, D. Huang, K. Hu, H. Chen, Z. Yuan, One-step production of biodiesel from wet and unbroken microalgae biomass using deep eutectic solvent, Bioresour. Technol. 238 (2017) 157-163. doi:10.1016/j.biortech.2017.04.038.

[50] T. Dong, E.P. Knoshaug, P.T. Pienkos, L.M.L. Laurens, Lipid recovery from wet oleaginous microbial biomass for biofuel production: A critical review, Appl. Energy. 177 (2016) 879-895. doi:10.1016/j.apenergy.2016.06.002.

[51] S.-J. Wu, S.-W. Shiah, W.-L. Yu, Parametric analysis of proton exchange membrane fuel cell performance by using the Taguchi method and a neural network, Renew. Energy. 34 (2009) 135-144. doi:10.1016/j.renene.2008.03.006.

[52] C. Rodriguez, A. Alaswad, Z. El-Hassan, A.G. Olabi, Mechanical pretreatment of waste paper for biogas production, Waste Manag. 68 (2017) 157-164. doi:10.1016/J.WASMAN.2017.06.040.

[53] K.Y. Benyounis, A.G. Olabi, Optimization of different welding processes using statistical and numerical approaches - A reference guide, Adv. Eng. Softw. 39 (2008) 483-496. doi:10.1016/j.advengsoft.2007.03.012.

[54] M.E. Montingelli, K.Y. Benyounis, B. Quilty, J. Stokes, A.G. Olabi, Influence of mechanical pretreatment and organic concentration of Irish brown seaweed for methane production, Energy. 118 (2017) 1079-1089. doi:10.1016/j.energy.2016.10.132.

[55] K.Y. Benyounis, A.G. Olabi, M.S.J. Hashmi, Multi-response optimization of CO2 laser-welding process of austenitic stainless steel, Opt. Laser Technol. 40 (2008) 7687. doi:10.1016/j.optlastec.2007.03.009. 
[56] H.A. Eltawahni, A.G. Olabi, K.Y. Benyounis, Effect of process parameters and optimization of CO2 laser cutting of ultra high-performance polyethylene, Mater. Des. 31 (2010) 4029-4038. doi:10.1016/j.matdes.2010.03.035.

[57] M. Virot, V. Tomao, C. Ginies, F. Visinoni, F. Chemat, Microwave-integrated extraction of total fats and oils, J. Chromatogr. A. 1196-1197 (2008) 57-64. doi:10.1016/j.chroma.2008.05.023.

[58] A. Guldhe, B. Singh, I. Rawat, K. Ramluckan, F. Bux, Efficacy of drying and cell disruption techniques on lipid recovery from microalgae for biodiesel production, Fuel. 128 (2014) 46-52. doi:10.1016/j.fuel.2014.02.059.

[59] F. Passos, M. Hernández-Mariné, J. García, I. Ferrer, Long-term anaerobic digestion of microalgae grown in HRAP for wastewater treatment. Effect of microwave pretreatment, Water Res. 49 (2014). doi:10.1016/j.watres.2013.10.013.

[60] M. Ali, I.A. Watson, Microwave treatment of wet algal paste for enhanced solvent extraction of lipids for biodiesel production, Renew. Energy. 76 (2015) 470-477. doi:10.1016/j.renene.2014.11.024.

[61] J.Y. Lee, C. Yoo, S.Y. Jun, C.Y. Ahn, H.M. Oh, Comparison of several methods for effective lipid extraction from microalgae, Bioresour. Technol. 101 (2010). doi:10.1016/j.biortech.2009.03.058.

[62] Y. Liang, T. Tang, T. Siddaramu, R. Choudhary, A.L. Umagiliyage, Lipid production from sweet sorghum bagasse through yeast fermentation, Renew. Energy. 40 (2012) 130-136. doi:10.1016/j.renene.2011.09.035.

[63] A. Alam, D. Vandamme, W. Chun, X. Zhao, I. Foubert, Z. Wang, K. Muylaert, Z. Yuan, Bioflocculation as an innovative harvesting strategy for microalgae, Rev. Environ. Sci. Biotechnol. 15 (2016) 573-583. doi:10.1007/s11157-016-9408-8.

[64] P. Biller, A.B. Ross, P. Biller, A.B. Ross, Hydrothermal processing of algal biomass for the production of biofuels and chemicals, 7269 (2017). doi:10.4155/bfs.12.42.

[65] J. Cheng, Y. Qiu, R. Huang, W. Yang, J. Zhou, K. Cen, Biodiesel production from wet microalgae by using graphene oxide as solid acid catalyst, Bioresour. Technol. 221 (2016) 344-349. doi:10.1016/j.biortech.2016.09.064.

[66] S. Balasubramanian, J.D. Allen, A. Kanitkar, D. Boldor, Oil extraction from Scenedesmus obliquus using a continuous microwave system - design, optimization, and quality characterization, Bioresour. Technol. 102 (2011) 3396-3403. doi:10.1016/j.biortech.2010.09.119. 